\title{
A CULTURA NA AMAZÔNIA: UMA TRADUÇÃO DA TRADIÇÃO EM CANÇÕES ACRIANAS DA NOSSA CONTEMPORANEIDADE
}

\section{CULTURE IN THE AMAZON: A TRANSLATION OF TRADITION IN ACRIAN SONGS OF OUR CONTEMPORARY}

Adriana Alves ${ }^{1}$

\section{RESUMO:}

Este trabalho nos convida a tecer algumas considerações sobre uma época classificada como pós-moderna, na verificação do caráter híbrido nas composições de Aarão Prado e Heloy de Castro autores pouco conhecidos, mas que mereceram estas considerações, porque podem ser lidos/ouvidos como entretenimento e crítica social. Neste sentido, as mudanças culturais são inerentes a este processo já que uma das características deste momento histórico é a constante transformação das ciências, do mundo e da visão que temos dele. Neste sentido, ao analisarmos as canções que desconstroem a história oficial do Acre estamos também exemplificando que a história oficializada é suscetível a mudanças, alterando assim toda uma visão cultural que se tinha até então, com possibilidades de vivenciar a maravilha e o mistério, das projeções fantasiosas e da observação da natureza inscritas ao longo do tempo na memória de uma população.

\section{PALAVRAS-CHAVE:}

Modernidade. Tradição. Tradução. Amazônia.

\section{ABSTRACT:}

This work invites us to make some considerations about a period classified as postmodern, in the verification of the hybrid character in the compositions of Aarão Prado and Heloy de Castro authors little known, but who deserved these considerations, because they can be read / heard as entertainment and social criticism. In this sense, cultural changes are inherent to this process since one of the characteristics of this historical moment is the constant transformation of the sciences, the world and the vision that we have of it. In this sense, when analyzing the songs that deconstruct the official history of Acre we are also exemplifying that the official history is susceptible to changes, altering thus a whole cultural vision that had until then, with possibilities of experiencing the wonder and the mystery, of the projections and the observation of nature inscribed over time in the memory of a population.

\section{KEYWORDS:}

Modernity. Tradition. Translation. Amazonia

1 Mestre em Letras pela Universidade Federal de Rondônia - UNIR/2017. Docente da disciplina de Leitura, interpretação e produção de textos nos cursos de Administração, Ciências Contábeis, Serviço Social e Psicologia, na Faculdade da Amazônia Ocidental FAA0/2017. E-mail: drycaalves25@gmail.com 


\section{Introdução}

$\mathbf{m}$ Tradição, tradução,
transparência, João de Jesus Paes Loureiro destaca que o sentimento estetizador e identitário de um povo principalmente na Amazônia, cujaculturagira em torno do eixo da poética do imaginário, revela transparência estetizadora da cultura atravessada pela luz de uma identidade que tem na aparência a sua essência. (2002, p.117)

Esse

sentimento socialmente compartilhado e recriado em símbolos expressivos valoriza essa forma estetizada e coletiva de estar em união. Assim, funcionam conforme Loureiro (2002), as expressões como: Boi-deParintins, o Carnaval, a Época Junina, o Boi Tinga, a Marajuda, o Pássaro Junino, por exemplo, na forma de um vitral estético atravessado pela luz de um sentimento de identidade regional ou nacional.

Desse modo, é no transbordamento afetivo que são construídas as relações entre os homens, dentre elas: a mestiçagem, a mobilidade social, a plasticidade do conjunto étnico. Essas relações afetivas contribuem para a constituição desse indivíduo, que tem a necessidade espontânea de se reconhecer como unidade enquanto sujeito que pertence a um lugar.

Para Loureiro, essas relações afetivas "abrem espaços à criação configurante desses vitrais estetizados de cultura" (2002, p.119). Para ele, nós estamos acostumados apenas com uma única representação estética de arte, qualquer evento que não se enquadre dentro desses padrões estereotipados, nos causa espanto e não representa para nós cultura.

Um exemplo utilizado por Loureiro (2002) é a manifestação cultural do boi de máscaras, também conhecido como boi-tinga, que acontece na cidade de São Caetano de Odivelas, no interior do Pará. Essa representação cultural foi hostilizada em detrimento do boi tradicional e há nesse movimento um desprezo que 
não leva em conta a cultura popular e o contexto histórico, social e cultural que interpelam os sujeitos que participam desse evento cultural. Assim, "toda forma de tradução assusta, porque, na verdade, temos uma tradição do uno, daquilo que é único. Tudo aquilo que se torna múltiplo acaba sendo punido" (LOUREIRO, 2002, p. 120).

Observar-se que compreender o processo da construção da cultura brasileira é altamente complexo, pois historicamente já está definida e resiste em não abrir espaço para discussões pluriculturais, para a tradução dessa cultura que está enraizada nos documentos oficiais. Um exemplo disso é o contexto da Torre de Babel, que contemplava todas as variantes linguísticas na comunicação entre os indígenas, na Amazônia. A busca por essa unicidade na tentativa de recear, banir a multiplicidade e plurivalência linguística obrigou aos colonizadores portugueses a criação da língua geral, com a finalidade de controlar a comunicação entre os índios.

Para Loureiro, tradução

é uma provocação da plurivalência. Penso até que toda tradução é uma forma de androgenia e acaba criando uma dupla sexualidade para o passado e para o futuro, e por isso abre a unidade do ser. Obviamente, porém, uma tradução realmente fascina, mais pelo intraduzível do que propriamente pelo traduzido. Mas, toda obra de arte não fascina mais pelo indizível do que propriamente pelo o que se diz? A tradução tem esse condão: todo aquele que se volta para traduzir, resguarda o intraduzível, ficando este como um vetor para as novas traduções, segundo o processo da "gestação consumatória". 0 que é gestação consumatória? É um provocar ininterrupto do novo através daquilo que está sendo. Portanto, eu creio que todos nós estamos voltados, como numa insurreição, para o desejo de tradução e, assim, procedemos a cada momento (LOUREIRO, 2002, p, 121).

Nessa

perspectiva, compreendemos o conceito de tradução como a interpretação da materialidade de um discurso que foi dito, analisando e trazendo a tona àquilo que não foi dito, entretanto que ficou subtendido por carregar 
uma ideologia dentro do contexto sócio-histórico, pelas condições de produção em que foram enunciados, e, sobretudo, pelos sujeitos enunciadores e interlocutores que produzem efeitos de sentido a materializar a língua.

Aqui, nessa reflexão, iremos fazer um recorte em nosso estudo abordando, duas canções intituladas "Acre Syndicate" e "Monotematicidade florestanica" compostas por cantores acrianos que tentam, através de suas letras, traduzirem a tradição da história oficial do Acre.

Aarão Prado e Heloy de Castro, através de suas composições musicais, nos mostram um horizonte em que a visão amazônica enquanto universo ecológico e histórico, façanha e sofrimento de indivíduos e coletividades. É nessa perspectiva que recorremos ao contexto histórico para que pudéssemos compreender a tradução do discurso da atual política de Governo que assenta suas bases num discurso sobre e para a floresta ancorados em projeto de desenvolvimento sustentável.

Como obra humana, a arte literária (aqui, consideramos a letra de música como poesia) se insere no tempo e no espaço acompanha a sociedade. Nesse sentido, condescendemos com Barthes ao afirmar que "a literatura faz girar os saberes, não fixa, não fetichiza nenhum deles; ela lhes dá um lugar indireto, e esse indireto é precioso" (BARTHES,1979, pp. 18-19). É o girar de saberes que nos permite depreender das canções em estudo, observar que há uma materialidade discursiva nos enunciados que nos permite diferentes efeitos de sentido sobre a história oficial acriana.

A canção "Acre Syndicate" foi composta por Heloy de Castro e João Veras, sendo interpretada por Heloy de Castro. Já "Monotematicidade Florestanica" foi escrita por Aarão Prado e Gilberto Lucas. As duas composições foram finalistas do concurso musical Festival Universitário da 
Canção, em 2003, realizado pela Coordenação de Eventos da Universidade Federal do Acre - UFAC.

Aarão Prado é radialista, vocalista, entusiasta, fazedor de cultura. Além de parceiro do "Coletivo Catraia", também escreve sobre festivais e bandas. 0 músico, cantor e compositor Heloy de Castro, nascido em Minas Gerais, na cidade de Rio Novo, representa um dos personagens que, através de suas canções, vem cultivando vivos os valores da cultura acriana. Suas composições relatam a magia da floresta, da natureza amazônica, de personagens da família, do dia a dia acriano, de coisas e valores simples, porém representativos da convivência também simples e da cultura da população local.

Pouco conhecida dos acrianos, essas composições nos despertaram o interesse por serem de cunho social e revelarem dentre outras coisas: o espaço e o homem acriano. Ao escolhermos as composições dos referidos autores como objeto de estudo, nosso interesse foi imediato, por serem construídas a partir de informações históricas, por acontecimentos que foram marcantes na vida do povo acriano.

Os relatos históricos sobre a conquista do Acre, os ditos populares, as lendas e os mitos presentes em nosso imaginário podem ser percebidos ainda hoje, quando um cidadão qualquer caminha pela cidade e se depara com monumentos e praças que evocam uma memória de nosso passado. Nas composições "Acre Syndicate" e "Monotematicidade Florestanica", se misturam discursos por meio da paródia, pastiche, ironia, diversão, ao trazer à tona elementos da micro-história do Acre, como por exemplo, à noite em que Plácido de Castro rende o Exército boliviano.

Desse modo, questões de delimitação das fronteiras entre o Norte do Brasil e a região da Bolívia, definidas de forma aleatória pelo Tratado de Ayacucho, de 27 de março de 1867, e a negociação 
denominada Bolivian Syndicate, que pretendia arrendar terras produtivas para o imperialismo norte-americano, além do Tratado de Petrópolis, são apenas alguns exemplos de questões históricas presentes nessas composições musicais, que, transformadas pela ironia $\mathrm{e}$ pelo humor, compõem o diálogo transgressor que faz um reconto da história de uma maneira mais reveladora e crítica, sem se pautar nas verdades prontas e acabadas reveladas pela mídia, o qual apresenta o sentido carnavalizado entre humor e verdades contadas de maneira que possam ser compreendidas facilmente.

\section{A euforia dos "1900"}

Foi no ano das comemorações dos 100 anos de anexação do Acre ao Brasil, que Heloy de Castro apresentou sua música "Acre Syndicate", mostrando que a história do Bolivian. Syndicate representou uma das formas de lucro com a exploração das riquezas do solo acriano. 0 autor utiliza uma linguagem satirizada, a partir da qual vem desconstruir a história oficial, traduzindo o indizível, aquilo que não foi dito, provocando a plurivalência de indagações para tradição do que os livros de história nos contaram e se realmente há o que comemorar nesses cem anos de Revolução.

Es temprano para La fiesta.

- Não é festa, intendente,

É revolução.

Seja lá o que tenha sido

Nessas terras

Em mil e novecentos

O meu presente pergunta

Para quem serviu a festa

Para quem serve a tal revolução

Desde o Bolivian Syndicate Até o Acre Syndicate.

A utilização da sátira será observada neste trabalho como um recurso que suscita o riso, como arma contra a alienação instaurada na Amazônia por ocasião do ciclo da borracha, em especial no período que vai de 1877 a 1900 . Por outro lado, esse posicionamento crítico e satírico assumido pelo o autor põe em cena as facetas representativas da época. Após cem anos do que "dizem" ter sido uma revolução, comemoramos a separação da Bolívia e anexação do Acre como território brasileiro. 
Quando o autor, no primeiro verso, utiliza o discurso que supostamente o comandante boliviano utilizou quando se viu abordado pelas tropas acrianas. "Es temprano para La fiesta". É porque os bolivianos não estavam esperando a invasão na madrugada, e houve esse devaneio de achar que havia alguma comemoração. De acordo com a historiografia acriana, Plácido de Castro teria respondido "Não é festa, intendente, É revolução."

Heloy de Castro nos indaga para o que realmente tenha acontecido em 1900 e nos dias de hoje, para quem serviu essa festa? Há o que realmente se comemorar? "Nunca é tarde para revolução". Nesse viés, o autor acriano coloca em cena a representação social de uma época por dois ângulos. Num primeiro momento, seu texto dialoga com a História do Acre, enquanto território, abordando o risível e o deboche sem nenhum compromisso com a história oficial.

Vamos festejar

Cem anos de tradição, Família e propriedade
De periferia sem rumo

Violentada pela ilusão eleitoral

Desde o Bolivian Syndicate Até o Acre Syndicate Vamos dar nomes aos donos, Das paredes da história Que levantam concretos, Alimentam mitos Pintam fachadas, Asfaltam reservas E cozinham a opinião Como se a coisa pública Fosse seu pé de fogão Desde o Bolivian Syndicate Até o Acre Syndicate Se "Es Temprano para La fiesta"

Nunca é tarde para a revolução.

Em um segundo momento, Heloy de Castro termina por afirmar que, se a Revolução não se realizou, ainda há tempo para que ela se realize, não tendo se esgotado nos 1900, apontando também, a possibilidade de uma revolução que pode ser feita a partir de ideias ou da própria arte. Um questionamento que se coloca, desde os tempos passados até hoje, a rescisão do contrato com o "Bolivian Syndicate" nos trouxe de fato a liberdade da manipulação dos empresários em nossas riquezas (reservas florestais)? 
Quando o autor, no último verso, afirma que nunca é tarde para a revolução, talvez seja porque de fato esta nunca ocorreu e que usa suas palavras para mostrar ao povo acriano que não se deve conformar com a realidade vivida, mas lutar por aquilo que se deseja, mostrando que as mudanças podem acontecer, mas precisam de um posicionamento da população que não pode ficar estanque vendo a vida passar sem ser parte da história, sem fazer história.

$\mathrm{Na}$ mesma direção de Castro, Aarão Prado em "Monotematicidade Florestanica" retrata em sua composição um momento histórico mais recente. Estamos diante de um texto que tece a caricatura de uma sociedade, que redefine sua identidade, como é o caso do Acre. Esse é um assunto desafiador, pois a história reclama o estatuto da verdade para os seus relatos, enquanto a literatura estabelece o estatuto da ficção, invenção, imaginação como marca de seu texto. Entretanto, "até que ponto o discurso ficcional não seria também o discurso da verdade, feito através da visão mágica que a criação permite" (SILVA, 1989, P.24).

Com efeito, a música "Monotematicidade Florestanica", ambientada no Estado do Acre/ Amazônia do século XXI, constrói seu enredo, a partir de um dado contexto histórico-social, o discurso político-administrativo em vigor há mais de uma década no Estado e que tem se pautado por ser um projeto de desenvolvimento sustentável e pela adoção de imagens identitárias relacionadas à floresta e à valorização de elementos culturais locais. Ou seja, Aarão Prado dialoga com o discurso histórico e através desse discurso, adota uma posição profundamente irônica e carnavalizada diante dos elementos que constituem o "processo de desenvolvimento" e a imagem identitária do Acre.

Vemo-nos diante de uma proposta de reflexão acerca dos fatos do passado com o objetivo de entender o presente. Temos como ponto de tensão logo no 
início da canção, um sujeito poético que nega a todos os consensos em relação à culinária local:

Posso não gostar de tapioca

E vomitar o açaí

Não vou falar de mandioca

Pra dizer que sou daqui

Eu odeio tacacá

E o amendoim do Quinarí.

Nunca fui ecologista

E nunca vi o Mapinguarí.

Adoro uma farofinha

Mas não vou saber dizer

Se a farinha é de Cruzeiro

Da Sadia ou da Nestlé.

Aarão Prado reescreve um dos aspectos importantes e que se faz presente como tradição nos dias atuais, escrevendo às avessas, num jogo de ironia, sarcasmo, elementos que são apreciados por pessoas de outros lugares, que conhecem o Acre como um espaço exuberante e exótico.

Em todo o Estado do Acre, existem muitas famílias envolvidas na produção de farinha de mandioca e derivados, como a farinha de tapioca, goma e biscoitos, esta produção concentra-se principalmente em Cruzeiro do Sul, no Vale do Juruá, região Noroeste do Estado. A tradição trata a farinha de Cruzeiro do Sul como sendo uma das melhores do Brasil.

Oaçaíé uma palmeira nativa encontrada em abundância que se constitui parte da cultura acriana, seu fruto tem alto valor nutritivo e tem fonte garantida de renda, sendo comercializado em todo o Estado, mas com grande exposição no Festival do Açaí, no município de Feijó que se configura um sucesso, pois veem pessoas de outros Estados para conhecer o sabor do Açaí do Acre.

Então, diante da abordagem dos diversos termos utilizados para definição de cultura, dáse maior importância à relação desses com a língua, à música, à arte e isso ocorre também com a comida, porque de certa forma esta tem um significado e uma incorporação de elementos da difusão cultural.

Por intermédio da culinária, a sociedade codifica mensagens que lhe permitem significar pelo menos uma parte do que ela é (GIARD, 1998. Isso ocorre, muitas vezes, de maneira inconsciente, já que 
é algo com que convivemos desde criança e faz parte da sociedade a qual pertencemos, por isso acabamos por não perceber como os hábitos alimentares colaboram para uma identificação do que somos e a que grupo pertencemos.

A sátira ao mito do Mapinguari é dessacralizadora de uma ordem. Consiste em uma denúncia de falsa consciência ideológica. Aarão Prado busca estabelecer um sentido para a paródia. Esta se manifesta fazendo uma relação de semelhança com o texto original. Lançando mão de uma linguagem, satírica, este acaba por subverter a visão historiográfica corrente, já que sua preocupação imediata não é registrar ou reiterar a versão oficial da história, mas dessacralizá-la e revelar o que há de engodo nela, daí sua opção pela comicidade e seus derivativos.

A paródia, a ironia, o esgar e a sátira mordaz, abordados por Loureiro, que remonta o intraduzível da tradução, exercendo um fascínio deliberado pelas palavras alcançando um entendimento que vai além do que o traduzido, vemos o autor da canção em seu processo de "gestação consumatória", provocando o novo, questionando a tradição da história oficial, transgredindo o conhecimento em busca de algo maior, verdadeiro, absoluto.

Optamos por uma abordagem que revela a carnavalização na leitura em "Monotematicidade Florestanica”, pois se observa no texto o dilema da ordem/ desordem presente no universo da música. Na tentativa de criar uma composição musical Aarão Prado utilizou uma lógica discursiva a qual Bakhtin chamaria de carnavalização. Este considera que o carnaval vai além, é uma visão de mundo que aproxima "o mundo do homem e o homem do mundo, onde as relações são livres, opondo-se ao sério oficial, que é apaixonado, monológico e dogmático, realizado, sobretudo, pelo medo da mudança no estado existente da 
ordem social" (BAKHTIN, 1981, p. 111). Assim, a carnavalização é uma forma de permitir novas experiências, descobertas até então insuspeitas.

Com efeito, ao recontar pela "ficção" esse seu "desgosto" pela culinária local, o escritor/ compositor acriano optou pela encenação cômica, ao invés de reafirmar a versão oficial dos relatos que conhecemos através da História, que é considerada mais séria e respeitável. Desse modo, vemos um caminho inverso, a qual a história oficial propõe, ou seja, reafirma-se algo do que Bakhtin aborda a inversão da ordem para a desordem. E a revelação como foi citado anteriormente, de um mundo às avessas, o que caracteriza o universo carnavalesco na letra de Aarão Prado.

Se Amazônia é mesmo nossa Pegue minha parte pra você Monte sua tribo

Mas cuidado com o que eu digo.

A crítica vai mais além, questiona-se a Amazônia Legal, se esta se constitui como parte do território acriano, e faz alusão ao conceito de florestania, criado por Antônio Alves, no final dos anos 80 e cunhado pelo Governo da Floresta, que tenta conciliar os ideais de uma sociedade sustentável, expressa por este conceito que tem norteado os últimos anos da atual gestão política, que tem exercido no Acre, "sonho cultivado por Chico Mendes" que seria defender a floresta, e uma nova relação entre o homem e a floresta.

Nesse caso, a sátira carnavalesca constitui-se em apresentar o descompasso da relação homem e natureza. Nesta relação esperam a ordem, mas quase todas as ações redundam numa desordem dessa sociedade, numa forma ambivalente, peculiar da forma carnavalesca de ver o mundo. Se a Amazônia é mesmo nossa porque houve essa dilapidação e invasão, em busca da abundância e qualidade da seringueira acriana que produzia uma excelente elasticidade, motivando um sistema de tráfico que invade a floresta? 
Aarão Prado aborda que "suas canções nasceram aqui em tempos de florestania." 0 que se refere ao projeto de desenvolvimento sustentável que seria o aproveitamento dos recursos naturais dentro de uma proposta de cuidado com a natureza. Em "Monotematicidade Florestanica" é revelado o avesso da sociedade com o objetivo de ampliar, assim, o significado da crítica social mostrandose avesso ao desenvolvimento sustentável no Acre e no Brasil.

As imagens do carnaval, identificadas no texto literário desempenham o desnudamento das estruturas simbólicas de poder e das instituições sociais. Essa cosmovisão carnavalizada aponta para uma liberdade sem limites na vida e na arte, constituindo-se numa forma de contestação social e política. E, nessa forma de ver o mundo, o riso detém um papel relevante, pois, ao mesmo tempo em que mostra o vício de modo engraçado, induz o leitor à reflexão e à crítica.

Nessa altura, cabe talvez uma pergunta: qual o sentido de carnavalização na construção da música de Aarão Prado? Uma das repostas, a essa questão, parece estar na forma paródica construtiva do texto irônico que se reflete em outro. Aarão Prado destrói tudo o que é empolado e estagnado sem destruir o núcleo autenticamente heróico da imagem (BAKHTIN, 1981, p.114).

Aarão Prado aponta o aspecto social ideologicamente marcado, que compõe a carnavalização e que nada mais é que a representação as avessas do sério-cômico, da ordem-desordem como foi citado anteriormente. Sob essa perspectiva discursiva, cabe esclarecer que nosso objeto de estudo constitui-se de comparar no campo da crítica social com "Acre Syndicate" - de Heloy de Castro, o qual se desenvolve na instância temporal do século XX, fase em que o Acre se constitui território boliviano e coloca em evidencia os emblemas da época, como políticos, revolucionários, estrangeiros e índios. Não 
podemos esquecer que, do ponto de vista cronológico, as composições musicais acreanas representam cronologicamente períodos históricos distintos, mas apresentam semelhança no que se refere à temática. Ambas terminam por realizar uma crítica social e desconstroem as versões oficiais da história da sociedade de sua época, utilizando uma linguagem satírica, irônica, acaba por construir carnavalização da história oficial.

Diante disso, a representação social expressa em "Acre Syndicate" no tocante ao item que trata do contrato com o "Bolivian Syndicate", que visava arrendar as terras do Acre para os empresários norte-americanos, observase que o discurso de Heloy de Castro elabora uma crítica profunda a comemoração dos Cem anos de Revolução Acriana, terminando por agir contra a ideologia dominante. Nessa perspectiva não se pode perder de vista "Monotematicidade Florestanica" de Aarão Prado que tem como alicerce discutir as questões que envolvem a formação identitária de diferentes níveis culturais.

Constatamos que Aarão Prado se propõe a fazer uma tradução crítica às representações culturais que se constituem como tradição no Acre e isso se configura a partir da culinária local, como por exemplo: a tapioca, o açaí, a farinha de Cruzeiro do Sul que são produtos naturais saborosos e saudáveis que por sua vez fazem parte da área verde acriana e tem sido explorados de forma indevida, mas por fazerem parte da cultura dos povos da floresta e os defensores da preservação da natureza que prezam pelo desenvolvimento sustentável e procuram proteger as riquezas naturais dos exploradores da Amazônia.

"Acre Syndicate" traz a tona uma narrativa que se caracteriza como gênero picaresco, destacando uma espécie de crítica à sociedade acriana do século $\mathrm{XX}$, e como se conduzia a política e a economia, sendo possível identificar os discursos 
que se perderam ao longo da história.

É interessante ressaltar que "Monotematicidade Florestanica", de Aarão Prado, é ambientada em uma época mais atual, empregando uma linguagem sob o signo da ironia que se constitui de uma desautorização da história oficial. Esta se realiza ao adotar uma posição crítica e nos leva a novos posicionamentos, a pensar que não existe uma única vereda de interpretação e que podemos refletir sobre as transfigurações e transformações da identidade do povo acriano. Essa possibilidade de interpretação vai de encontro com a multiplicidade de tradução, questionando uma única vertente, e abrindo o leque das possibilidades para compreender a história que não foi contada, que até então se constituiu indizível.

Nesse

prisma temático, é bom falar que em "Monotematicidade Florestanica", quando o autor cita:
Tá cheio de Curumim

Dando uma de E.T.

Pois hoje índio quer apito

Banho quente e DVD.

(...) Que tudo agora é sustentável

É só isso o que se pode cantar Nossa cultura é induzida.

Vemos a identidade dos povos indígenas fragmentada, alterada, ao evidenciarmos sua cultura e seus costumes. 0 homem indígena a partir do conhecimento da cultura do homem branco, não quer mais viver na sua tribo, junto com o povo da aldeia, pelo fato das influências do homem branco, houve essa aculturação que aconteceu por causa desses longos períodos de convivência. 0 que se explica pelo conceito de hibridização cultural, de acordo com Canclini, é "um processo em constante transformação, diferenciando-se da tradicional visão patrimonialista, adotando uma postura de mobilidade e ação" (CANCLINI, 2008). As raízes acrianas são hibridas, a população é orgulhosamente hospitaleira, talvez por isso,

Essa é uma tendência de mobilidade, que indica movimento é uma característica 
da modernidade que no contato com outras culturas é um meio de interação entre os diferentes povos. Passamos a conhecer e a conviver com muitas identidades que chegam até nós, e sem nos darmos conta, acabamos por absorver a cultura do outro, termo discutido por Canclini como hibridação, que se define como "processos socioculturais nos quais estruturas ou práticas culturais, que existem de forma separada, combinam-se para gerar novas estruturas, objetos e práticas" (CANCLINI, 2008).

Marshall Berman em seu livro Tudo o que é sólido desmancha no ar - a aventura da modernidade, ao mapear as aventuras e horrores, as ambigüidades da vida moderna, exemplifica com a visão de Marx esse ambiente moderno:

Todas as relações fixas, enrijecidas, com seu travo de antiguidade e veneráveis preconceitos e opiniões, foram banidas; todas as novas relações se tornam antiquadas antes que cheguem a se ossificar. Tudo o que é sólido desmancha no ar, tudo o que é sagrado é profanado, e os homens finalmente são levados a enfrentar (...) as verdadeiras condições de suas vidas e suas relações com seus companheiros humanos (BERMAN, 1986, p. 20).

$\mathrm{Na}$ esteira de Berman, é possível afirmar que aqui reside uma das razões pelas quais a canção de Aarão Prado enfatize que "nossa cultura é induzida", pois, nessa incorporação de elementos com o contato com outras culturas, podemos aceitar ou rejeitar esses elementos. Prado carrega em seu discurso a ideologia que aceitamos essa aculturação e assim nos tornamos "induzidos". A desconstrução desse emblema de desenvolvimento sustentável efetiva-se como uma crítica cuja finalidade nos conduz a inúmeras indagações sobre as estruturas sociais construídas no Estado do Acre e mostra uma temática em "Monotematicidade Florestanica" que expõe um cenário que aborda o auge do projeto de desenvolvimento sustentável. No entanto, traz à tona a ironia e termina por caricaturar o quadro econômico, social e cultural 
acriano.

Em síntese, a intertextualidade entre Heloy de Castro e Aarão Prado constroem uma crítica social, na qual duas composições musicais compreendem o período histórico do século XX e XXI, descaracterizando e fazendo cair por terra à mentalidade de uma única postura calcada no ideal da história oficial. Dessa forma, justifica-se a escolha das composições escritas por autores que se propuseram a escrever músicas que retratem o outro lado da historiografia acriana, ou seja, a tradução do processo de "gestação consumatória" abordada por Loureiro no inicio deste trabalho, que tira da aura do "UNO" da tradição da história oficial e nos leva ao novo, nos instiga a romper com os emblemas estendidos ao longo do percurso histórico. Baseado nisto, acreditamos que a cultura na Amazônia seja um misto dos dois: uma tradução da tradição e tudo o que sólido se desmancha no ar, já que ambas as proposições sugerem movimento. Para se adaptar aos tempos modernos a cultura tem de se modificar, tendo em vista que, a cultura não é estável, neste sentido ela necessita ser traduzida para a modernidade.

Nesse aspecto, discordamos do autor/cantor ao tecer sua crítica sob o desejo de modernização dos indígenas, acreditamos que isso é apenas mais uma prova desta mudança significativa. $\mathrm{Na}$ imagem abaixo, é possível visualizar, por exemplo, os índios Ashaninka e pode-se perceber que trocaram arco e fecha pelo computador, passando a utilizar meios tecnológicos para ajudar no combate aos madeireiros ilegais, agora em vez de brigas em que se corria o risco de perder pessoas, ganharam conhecimento tecnológico, para lutar pelas causas que defendem. 
Ashaninka utilizando computadores

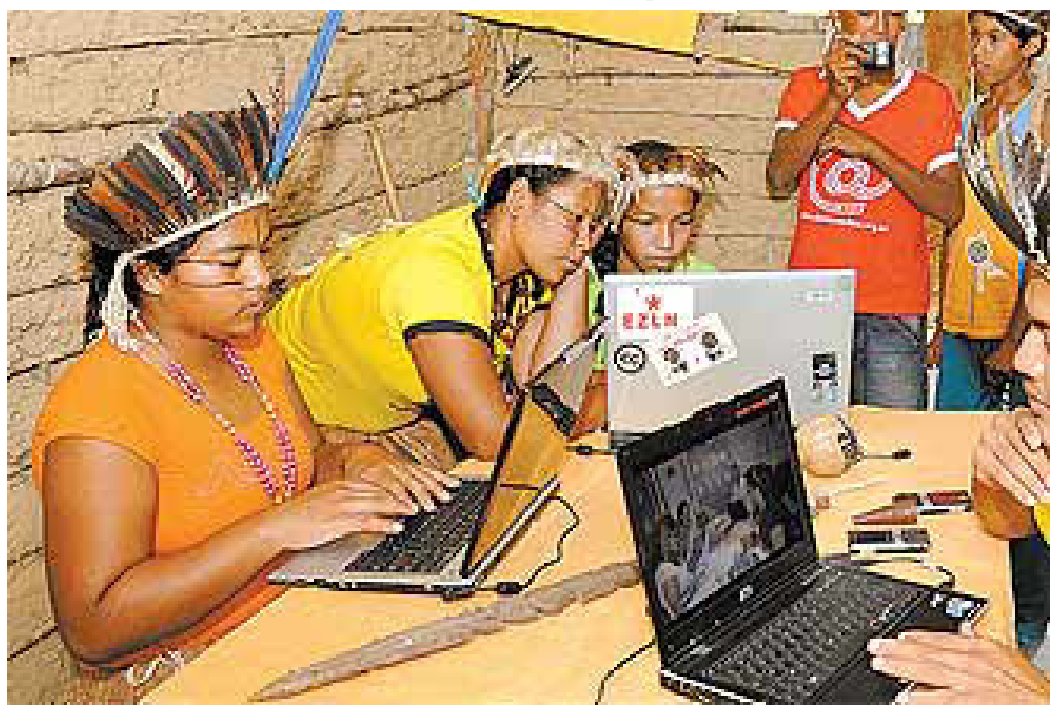

Fonte: http://www.conexaoaluno.rj.gov.br/especiais-19a.asp

A tradição não permanece tal como era quando não havia outras influências externas advindas de outros locais. As lendas indígenas representadas na atualidade se traduziram para espetáculos gigantescos cheios de alegorias mecânicas e com efeitos especiais, a oralidade por si só não consegue dar conta e por isso a criação de festivais como o de Parintins que mistura espetáculo com tradições mitológicas indígenas e tecnologia. A tradição não é totalmente desmanchada, mas é traduzida para a linguagem que o século XXI demanda, cada vez mais tecnológico.

\section{Considerações Finais}

Ahistóriaoficializadatornase fruto da pós-modernidade, uma vez que as certezas são questionadas o tempo todo, e a partir das dúvidas oriundas dos questionamentos é que se pode verificar os equívocos da história e recuperar os discursos dispersos ao longo dos anos, fazendo com que a suposta verdade que transita no meio social torne-se não a única, mas uma das possibilidades do mundo multi em que vivemos.

Ao remeter o caráter hibrido das composições de 
Aarão Prado e Heloy de Castro, pode-se perceber que tem a ver com as acreanidades, fato que existem muitas palavras no vocabulário acriano que outras pessoas não as reconhecem, por isso foi necessário se criar um minidicionário de acreanês, escrito por Antônio Klemer em 2002, para que as pessoas que visitam o Acre consigam entender a linguagem de maneira prática.

As mudanças culturais que ocorrem são necessárias, principalmente na situação em que se requer conhecimentos tecnológicos, deixamos de viver tempo histórico para viver momento histórico, em que tudo passa muito rápido, com as tecnologias as coisas mudam em instantes e com as histórias locais não é diferente, tudo depende da visão de um povo, pois na época em que foi escrita a história a visão do povo era aquela historiada, se forem reescritas numa visão de atualidade, muito do que foi tido como pronto e acabado mudaria. As letras das canções apenas mostram a realidade, mesmo sendo tratadas como desconstrução histórica, a cultura não é induzida, ela é vivenciada e moldada de acordo com o nível de conhecimento de um povo.

Viver as maravilhas e os mistérios das histórias contadas pelos idosos acrianos faz com que se projete um Acre naturalmente construído por um povo guerreiro, mas se contado por um jovem vai mudar toda a concepção de povo acolhedor e hospitaleiro e a visão passada vai de encontro às atualidades, esquecendo as projeções fantasiosas e as observações da natureza que fizeram parte da concepção histórica do Acre e que foram firmadas ao longo do tempo na memória da população.

Os autores das canções desconstroem os discursos oficializados e trazem à tona um novo ponto de vista sobre a história e a cultura. Ao fazerem isso, colocam em pauta a discussão crítica acerca da história e dos modelos culturais colocados como únicos e inquestionáveis, trazem à 
tona através das canções um novo mundo, já que traduzem a tradição sob uma nova perspectiva, resignificando a cultura através da ironia que não só desconstrói mas também dá caminho para novas possibilidades de interpretação da realidade.

\section{Referências}

ACRE. Fundação de Tecnologia do Estado do Acre. Atlas do Estado do Acre. Rio Branco- Acre, 2008. ALVES, A. "Florestania", In: 1o Encontro Internacional de Jornalismo Ambiental da Amazônia, 2003. Disponível em: Acedido em: 06.02.2010 BAKHTIN, M. Acultura popularna Idade Média e no Renascimento: o contexto de François Rabelais. Tradução de Yara Frateschi Vieira. São Paulo: Editora Hucitec, 1987. BAKHTIN, M. Problemas da poética de Dostoievski. Trad. Paulo Bezerra. Rio de Janeiro: Forense, 1981.

BARTHES, R. Aula. Tradução de Leyla Perrone-Móises. São Paulo: Editora Cultrix, 1990.

BERMAN, M. Tudo que é sólido desmancha no ar: a aventura da modernidade. Introdução: Modernidade - Ontem, Hoje e Amanhã. São Paulo: Cia das Letras, 1986.

GIARD, L. A arte de nutrir, In: CERTEAU, M.; GIARD, L.; MAYOL, P. A invenção do cotidiano: 2 - morar, cozinhar. Rio de Janeiro: Petrópolis: Vozes, 1998.

KLEMER, A. Manual de sobrevivência na terra onde o cupuaçu abunda. Rio Branco (AC): Antônio Klemer, 2002.

LIMA, S. S. Carnavalização e sátira na Amazônia de Galvez: estudo de hibridização cultural. Rio Branco (AC): Cia. Irreverentes, 2008.

RANZI, C. M. D. Raízes do Acre. Rio Branco (AC): Edufac, 2008.

SAN' TANA, A. R. Paródia, paráfrase \& Cia. São Paulo: Ática, 1985.

SILVA, T. C. C. José Saramago. Entre a História e a Ficção: uma saga de Portugueses. Lisboa: Dom Quixote, 1989.

SOUZA, R. F. Heloy de Castro em defesa da floresta. Disponível em: https://goo.gl/DUqDh3. Acesso em: 17 de Agosto de 2010.

Data de recebimento: 01/12/2017

Data de aceite: 26/12/2017 